\title{
Three-dimensional imaging system for colonoscopy
}

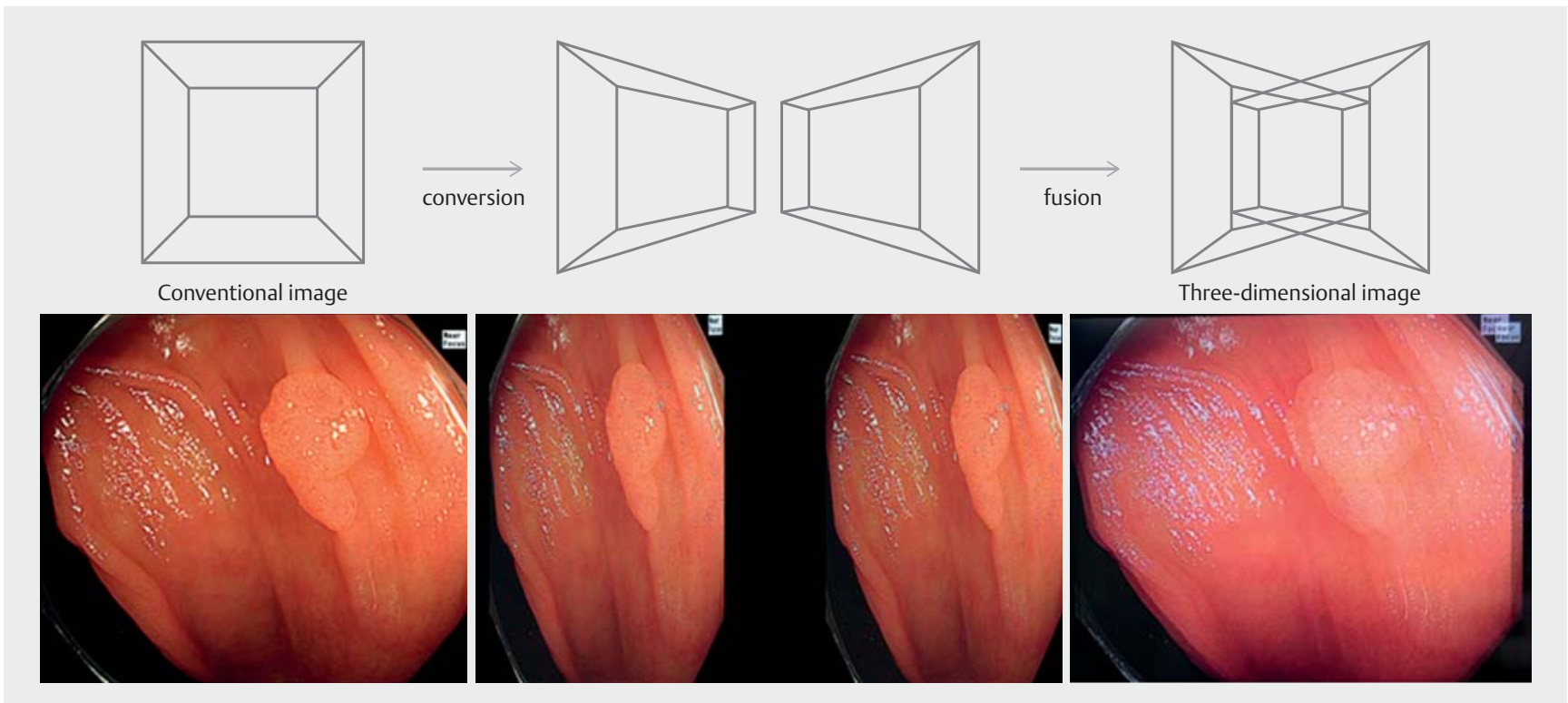

- Fig. 1 Explanation of a 3D image system. The 2D endoscopic image can be converted to a 3D image in real time.

Three-dimensional (3D) imaging techniques have been developed in the medical field. In laparoscopic surgery, such techniques are widely used; they provide the surgeon with spatial information and increase the safety of surgical techniques [1-3]. In gastrointestinal endoscopy, Sakata et al. reported the efficacy of 3D imaging for improved detection of colonic lesions using simulated $3 \mathrm{D}$ colonoscopy [4]. However, to create a conventional $3 \mathrm{D}$ image, two optical axes are required.

A novel $3 \mathrm{D}$ imaging processor (HD-3D-A; Shinko Optical, Tokyo, Japan), which can create $3 \mathrm{D}$ virtual video images from conventional two-dimensional (2D) endoscopic video images, has been developed recently [5]. This imaging processor is connected to a monocular endoscopic system and converts conventional endoscopic images into a pair of images, as if they were obtained from two different points that match the operator's convergence angle [4] (> Fig.1). This system can be used in combination with a conventional endoscope, and $3 \mathrm{D}$ images can be easily viewed using 3D glasses and a $3 \mathrm{D}$ monitor.

Here for the first time, we report the use of this $3 \mathrm{D}$ system in gastrointestinal endoscopy. In gastrointestinal endoscopy, the 3D image also provides the endoscopist with space perception, helping them to evaluate the status of the intestinal tract space ( $\nabla$ Video 1 ). In addition, we can more precisely visualize the
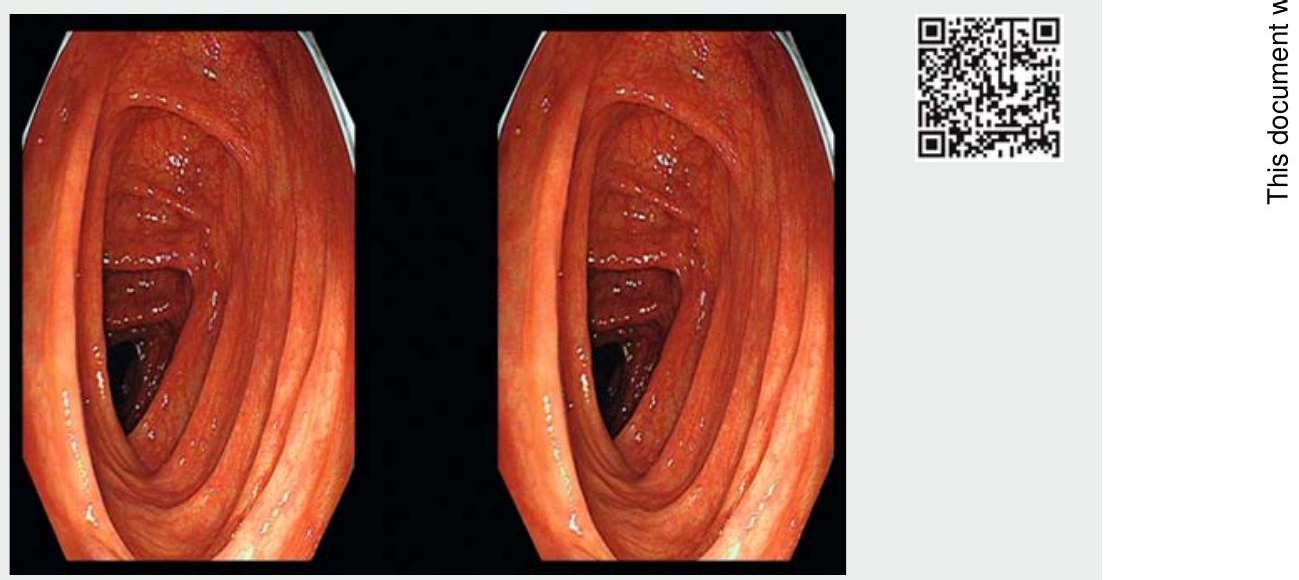

$\checkmark$ Video 1 Three-dimensional (3D) colonoscopy in a patient with a colonic adenoma. This video is presented in a side-by-side format. The $3 \mathrm{D}$ version can be viewed using the $3 \mathrm{D}$ video equipment. 
shape of a gastrointestinal tumor using a $3 \mathrm{D}$ image compared with a 2D image ( Video 1). During colonoscopy, 3D images provide visual cues to the next fold and aid in easy insertion to the cecum. Although further studies are required to demonstrate the efficacy of a $3 \mathrm{D}$ system in gastrointestinal endoscopies, we believe this system may have additional benefits compared with a conventional 2D endoscopy.

Endoscopy_UCTN_Code_TTT_1AQ_2AJ

\section{Competing interests}

None

\section{The Authors}

Tomoaki Matsumura', Hideaki Ishigami ${ }^{1}$, Kenichiro Okimoto ${ }^{1}$, Daisuke Maruoka', Tomoo Nakagawa', Mai Fujie², Makoto Arai ${ }^{1}$

1 Department of Gastroenterology and Nephrology, Graduate School of Medicine, Chiba University, Chiba City, Japan

2 Clinical Engineering Center, Chiba University Hospital, Chiba City, Japan
Corresponding author

\section{Makoto Arai, MD}

Department of Gastroenterology, Graduate School of Medicine, Chiba University, Inohana 1-8-1, Chiba-City, 260-8670, Japan Fax: +81-43-2262088

araim-cib@umin.ac.jp

\section{References}

[1] van Bergen P, Kunert W, Buess GF. Threedimensional (3-D) video systems: bi-channel or single-channel optics? Endoscopy 1999; 31: 732-737

[2] Votanopoulos K, Brunicardi FC, Thornby ] et al. Impact of three-dimensional vision in laparoscopic training. World J Surg 2008; 32: $110-118$

[3] Sakata S, Watson MO, Grove PM et al. The conflicting evidence of three-dimensional displays in laparoscopy: a review of systems old and new. Ann Surg 2016; 263: 234-239

[4] Sakata S, Grove PM, Stevenson AR et al. The impact of three-dimensional imaging on polyp detection during colonoscopy: a proof of concept study. Gut 2016; 65: 730-731

[5] Yoshida S, Kihara K, Fukuyo T et al. Novel three-dimensional image system for transurethral surgery. Int J Urol 2015; 22: 714 715

\section{Bibliography}

DOI https://doi.org/10.1055/s-0043-105572

Endoscopy 2017; 49: 716-717

(c) Georg Thieme Verlag KG

Stuttgart · New York

ISSN 0013-726X

\section{ENDOSCOPY E-VIDEOS}

https://eref.thieme.de/e-videos

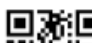

Endoscopy E-Videos is a free

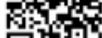
access online section, reporting on interesting cases and new

techniques in gastroenterological endoscopy. All papers include a high quality video and all contributions are freely accessible online.

This section has its own submission website at https://mc.manuscriptcentral.com/e-videos 